\title{
Responses of five small mammal species to micro-scale variations in vegetation structure in secondary Atlantic Forest remnants, Brazil Thomas Püttker ${ }^{\dagger 1}$, Renata Pardini ${ }^{\dagger 2}$, Yvonne Meyer-Lucht ${ }^{\dagger 1}$ and Simone Sommer*1
}

\begin{abstract}
Address: ${ }^{1}$ Leibniz-Institute for Zoo- and Wildlife Research, Alfred-Kowalke-Str. 17, D-10315 Berlin, Germany and ${ }^{2}$ Universidade de São Paulo, Instituto de Biociências, Rua do Matão, travessa 14, 101/Departamento de Zoologia, Cidade Universitária, 05508-900, Sao Paulo, Brasil

Email: Thomas Püttker - thomaspuettker@izw-berlin.de; Renata Pardini - renatapardini@uol.com.br; Yvonne Meyer-Lucht - meyerlucht@izwberlin.de; Simone Sommer* - sommer@izw-berlin.de

* Corresponding author †Equal contributors
\end{abstract}

Published: 5 May 2008

BMC Ecology 2008, 8:9 doi:10.1186/1472-6785-8-9

This article is available from: http://www.biomedcentral.com/1472-6785/8/9

(c) 2008 Püttker et al; licensee BioMed Central Ltd.

This is an Open Access article distributed under the terms of the Creative Commons Attribution License (http://creativecommons.org/licenses/by/2.0), which permits unrestricted use, distribution, and reproduction in any medium, provided the original work is properly cited.
Received: 17 October 2007

Accepted: 5 May 2008

\begin{abstract}
Background: The Brazilian Atlantic Forest is highly endangered and only about $7 \%$ of the original forest remains, most of which consists of fragments of secondary forest. Small mammals in the Atlantic Forest have differential responses to this process of fragmentation and conversion of forest into anthropogenic habitats, and have varying abilities to occupy the surrounding altered habitats. We investigated the influence of vegetation structure on the micro-scale distribution of five small mammal species in six secondary forest remnants in a landscape of fragmented Atlantic Forest. We tested whether the occurrence of small mammal species is influenced by vegetation structure, aiming to ascertain whether species with different degrees of vulnerability to forest fragmentation (not vulnerable: $A$. montensis, $O$. nigripes and $G$. microtarsus; vulnerable: $M$. incanus and $D$. sublineatus; classification of vulnerability was based on the results of previous studies) are associated with distinct vegetation characteristics.
\end{abstract}

Results: Although vegetation structure differed among fragments, micro-scale distribution of most of the species was influenced by vegetation structure in a similar way in different fragments. Among the three species that were previously shown not to be vulnerable to forest fragmentation, $A$. montensis and $G$. microtarsus were present at locations with an open canopy and the occurrence of $O$. nigripes was associated to a low canopy and a dense understory. On the other hand, from the two species that were shown to be vulnerable to fragmentation, $M$. incanus was captured most often at locations with a closed canopy while the distribution of $D$. sublineatus was not clearly influenced by micro-scale variation in vegetation structure.

Conclusion: Results indicate the importance of micro-scale variation in vegetation structure for the distribution of small mammal species in secondary forest fragments. Species that are not vulnerable to fragmentation occurred at locations with vegetation characteristics of more disturbed forest, while one of the species vulnerable to fragmentation was found at locations with older forest characteristics. Results suggest that micro-habitat preferences may be an important factor influencing the capacity of small mammals to occupy altered habitats and, consequently, their vulnerability to forest fragmentation at a larger spatial scale. 


\section{Background}

The coastal Atlantic Forest is one of the most diverse, and most threatened, natural environments in the world [1]. Due to severe human impact over the last few centuries most of the primary coastal Atlantic Forest has been destroyed. Only $7 \%$ of its original extent remains [1] and a considerable part of remaining forest takes the form of secondary forest fragments at different stages of regeneration, embedded in a rural or urban matrix [2,3]. In fragmented landscapes such as these, both the stage of regeneration and the degree of fragmentation influence forest structure within the fragments, which in turn determines habitat suitability and affects species occurrence as well as the composition of animal communities [4,5]. Since secondary forests may play an important role in species conservation if primary forest habitats are limited [5], it is important to understand which factors determine species distribution in secondary forests.

Although small mammals play a key role in neotropical forest ecosystems, including the Atlantic Forest, in terms of seed dispersal [6-11], dispersal of mycorrhizal fungi [12] and predation on seedlings $[7,10,13,14]$, only a limited number of studies focused on the influence of vegetation structure on small mammal distribution in secondary Atlantic Forest fragments [15-17].

The effects of forest fragmentation on Atlantic Forest small mammals vary among species. Some species are able to persist in isolated fragments and cross or occupy nonnative vegetation in human-altered areas, while others are restricted to large and/or connected forest remnants [16,18-22]. Since vulnerability to fragmentation is influenced by the capacity to occupy the altered habitats of the matrix [19,21,23-25], it is expected that preferences on a microhabitat scale in forested habitats will vary among species showing different degrees of vulnerability to forest fragmentation on a larger scale.

The identification of the scale that best explains variation in presence or abundance of organisms is a major goal in ecology [26]. This implies the necessity of examining ecological patterns on different scales. The issue of the "correct" scale at which assessment of biological parameters should be carried out has been the topic of numerous studies in ecology [27-32]. In fact, in his review Jorgensen [32] called attention to the lack of consistent use of the appropriate scale in small mammal microhabitat research and that broad but widely accepted generalizations (e.g. habitat partitioning, relation between abundance and availability of microhabitat) might be based on results that often confound micro- and macro-habitat effects.

In a recent study on small mammals in Caucaia do Alto, São Paulo, Pardini et al. [16] showed that three rodent and two marsupial species were affected in different ways by fragmentation on a macro-scale. The rodents Akodon montensis Thomas, 1902, and Oligoryzomys nigripes (Olfers, 1818) as well as the marsupial Gracilinanus microtarsus (Wagner, 1842) were not affected by fragmentation while the rodent Delomys sublineatus (Thomas, 1903) and the marsupial Marmosops incanus (Lund, 1840) decreased in abundance in smaller and/or more isolated fragments. In the same region, Umetsu \& Pardini [21] showed that the three species not affected by fragmentation were able to occupy anthropogenic habitats while the species vulnerable to fragmentation were restricted to native vegetation on a macro-habitat scale $[16,21]$.

In the present study we extended the previous work by adding a smaller scale to the investigation of small mammal habitat preferences in the same Atlantic Forest study area. While Umetsu and Pardini [21] studied the response of Atlantic Forest small mammal populations to habitat variation, this study deals with the response of small mammal individuals to micro-habitat differences. Specifically, we investigated the influence of vegetation structure on the micro-scale distribution of three small mammal species not affected by fragmentation (Akodon montensis, Oligoryzomys nigripes, Gracilinanus microtarsus) and two species vulnerable to fragmentation (Delomys sublineatus, Marmosops incanus) in six secondary forest remnants in the Atlantic Forest fragmented landscape of Caucaia do Alto. We investigated if the occurrence of small mammal species is influenced by vegetation structure, aiming to ascertain whether species with different degrees of vulnerability to forest fragmentation are associated with distinct vegetation characteristics.

\section{Results \\ Species captured}

In total, 698 individuals belonging to 12 species were captured 1597 times in 14400 trap nights, resulting in a trap success of $11.1 \%$. The five focus species were the most common species in the studied sites: the terrestrial rodents Akodon montensis and Delomys sublineatus, the scansorial rodent Oligoryzomys nigripes, the scansorial marsupial Marmosops incanus and the arboreal marsupial Gracilinanus microtarsus (Table 1), which accounted for $76.8 \%$ of individuals captured.

Additional species captured were the sigmodontine rodents Juliomys spp. (Osgood, 1933, 32 individuals), Euryoryzomys russatus (Wagner, 1848, 20), Sooretamys angouya (Fischer, 1814, 26), Brucepattersonius soricinus (Thomas, 1896, 5), Thaptomys nigrita (Lichtenstein, 1829, 58) and the didelphid marsupials Didelphis aurita (WiedNeuwied, 1826, 23) and Monodelphis americana (Müller, 1776, 14), and Micoureus paraguayanus (Tate, 1931, 1). 
Table I: Investigated species.

\begin{tabular}{|c|c|c|c|c|}
\hline Species & Locomotion habits & Number of individuals captured & Trap locations used & $\begin{array}{c}\text { Percentage of trap locations with more than } \\
\text { one individual captured }\end{array}$ \\
\hline Akodon montensis & terrestrial & $284(140 / 138 / 6)$ & 230 & 34.35 \\
\hline Oligoryzomys nigripes & scansorial & $46(33 / 13)$ & 38 & 15.79 \\
\hline Delomys sublineatus & terrestrial & $83(37 / 43 / 3)$ & 81 & 16.05 \\
\hline Marmosops incanus & scansorial & $64(33 / 31)$ & 72 & 9.72 \\
\hline Gracilinanus microtarsus & arboreal & $59(25 / 33 / 1)$ & 58 & 13.79 \\
\hline
\end{tabular}

Locomotion habits $([58,59]$ and own observations) of the investigated species, number of individuals captured (numbers of males, females and unsexed individuals are given in parenthesis), number of used trap locations and percentage of trap locations where more than one individual of the same species was captured.

In several trap locations more than one individual of the same species was captured (Table 1). In the case of Akodon montensis, the percentage of traps with more than one individual of the same species was $34.35 \%$ (Table 1). For all other species, however, the percentage of traps with more then one individual of the same species was below $20 \%$ (Table 1).

\section{Principal component analysis to identify major traits of variation in vegetation structure}

The vegetation characteristics were reduced to three principal components (PC1, PC2, PC3) with an Eigenvalue greater than one, which explained $69.9 \%$ of the variance in the data (Table 2). The factor loadings are a measure of the correlation between original habitat variables and the new variables (PC's, [33]). The correlation matrix (Table 2) revealed that the first principal component, which explained $33.9 \%$ of the variance, described the canopy height and the density of the vegetation up to three meters. The second principal component $(20.5 \%$ variance explained) reflected the amount of bamboo and the number of horizontal structures while the third (15.5\% variance explained) described the density of the canopy (Table 2).

Table 2: Factor loadings of Principal Components.

\begin{tabular}{lccc}
\hline & PCI & PC2 & PC3 \\
\hline Eigenvalue & 2.37 & 1.44 & 1.09 \\
Variance explained & 33.88 & $20.5 \mathrm{I}$ & 15.50 \\
cumulative Variance & 33.88 & 54.39 & 69.89 \\
\hline Canopy cover & & & \\
Canopy height & -0.11 & -0.09 & 0.96 \\
Vegetation density 0 - 0.5 m & -0.69 & 0.02 & 0.24 \\
Vegetation density 0.5 - I.5 m & 0.80 & -0.23 & -0.05 \\
Vegetation density 1.5 - 3 m & 0.87 & 0.12 & -0.03 \\
Amount of Bamboo & 0.69 & 0.42 & 0.17 \\
Amount of horizontal structures & 0.03 & 0.75 & 0.08 \\
& -0.02 & 0.78 & -0.28 \\
\hline
\end{tabular}

Eigenvalues, variance explained and correlations (factor loadings) between the three principal components and vegetation characteristics.

\section{Species response to micro-scale variation in vegetation structure}

The vegetation structure synthesized by all principal components differed among fragments (two-factorial ANOVA; Table 3 ). Species response to these major trends of vegetation structure variation, however, was in most cases independent of the fragment considered.

Species non-vulnerable to fragmentation

$O$. nigripes was captured at trap locations with a significant higher mean value for PC1 (Table 3; Fig. 1), meaning a lower canopy and denser understory vegetation. No significant difference was found between used and unused trap locations considering PC2 or PC3 (Table 3; Fig. 1), as well as, no significant interaction between factors (FRAGMENT*USE; Table 3).

The marsupial G. microtarsus was captured at locations with a lower mean value for PC3 (Table 3; Fig. 1) i.e. locations with lower canopy cover. Mean values between used and unused trap locations did not differ significantly in PC1 or PC2 (Table 3; Fig. 1) and again no significant interaction between factors (FRAGMENT*USE) was found (Table 3).

For A. montensis, there was a significant difference between used and unused trap locations in all principal components (Table 3). Significant interactions between factors FRAGMENT*USE, however, was observed for PC1 and PC2 (Table 3), indicating that the influence of vegetation structure synthesized in these two principal components on the species distribution was depended on the fragment considered. Irrespective of the fragment, however, A. montensis similarly to G. microtarsus was captured in trap locations with a significantly lower mean value for PC3, i.e. lower canopy cover (Fig. 1).

Species vulnerable to fragmentation

For $D$. sublineatus, mean values did not differ significantly between used and unused trap locations (Table 3; Fig. 1) as well as no significant interaction between factors FRAG- 
Table 3: Full results of 2-way-ANOVA. Results of 2-way-ANOVA for all species and all three principal components.

\begin{tabular}{|c|c|c|c|c|c|c|}
\hline & & SS & DoF & MS & $\mathrm{F}$ & $p$ \\
\hline \multirow[t]{18}{*}{ Oligoryzomys nigripes } & PCI & & & & & \\
\hline & Intercept & 34.19 & I & 34.19 & 32.26 & $<0.0001$ \\
\hline & Fragment & 10.67 & 3 & 3.56 & 3.36 & 0.019 \\
\hline & Use & 8.57 & 1 & 8.57 & 8.09 & 0.005 \\
\hline & Fragment*Use & 4.58 & 3 & 1.53 & 1.44 & 0.230 \\
\hline & Error & 424.00 & 400 & 1.06 & & \\
\hline & PC2 & & & & & \\
\hline & Intercept & 0.00 & I & 0.00 & 0.00 & 0,970 \\
\hline & Fragment & 13.60 & 3 & 4.53 & 3.71 & 0.012 \\
\hline & Use & 1.53 & 1 & 1.53 & 1.26 & 0.263 \\
\hline & Fragment*Use & 7.89 & 3 & 2.63 & 2.15 & 0.093 \\
\hline & Error & 488.47 & 400 & 1.22 & & \\
\hline & PC3 & & & & & \\
\hline & Intercept & 1.02 & 1 & 1.02 & 1.26 & 0.262 \\
\hline & Fragment & 18.81 & 3 & 6.27 & 7.78 & $<0.0001$ \\
\hline & Use & 1.24 & 1 & 1.24 & 1.54 & 0.215 \\
\hline & Fragment*Use & 2.58 & 3 & 0.86 & 1.07 & 0.364 \\
\hline & Error & 322.46 & 400 & 0.81 & & \\
\hline \multirow[t]{18}{*}{ Gracilinanus microtarsus } & PCI & & & & & \\
\hline & Intercept & 4.53 & I & 4.53 & 4.72 & 0.030 \\
\hline & Fragment & 27.51 & 4 & 6.88 & 7.16 & $<0.0001$ \\
\hline & Use & 0.00 & I & 0.00 & 0.00 & 0.962 \\
\hline & Fragment*Use & 5.28 & 4 & 1.32 & 1.37 & 0.242 \\
\hline & Error & 481.41 & 501 & 0.96 & & \\
\hline & PC2 & & & & & \\
\hline & Intercept & 0.26 & I & 0.26 & 0.25 & 0.618 \\
\hline & Fragment & 20.80 & 4 & 5.20 & 4.98 & 0.001 \\
\hline & Use & 0.85 & 1 & 0.85 & 0.82 & 0.367 \\
\hline & Fragment*Use & 6.49 & 4 & 1.62 & 1.55 & 0.186 \\
\hline & Error & 523.52 & 501 & 1.04 & & \\
\hline & PC3 & & & & & \\
\hline & Intercept & 2.46 & I & 2.46 & 2.97 & 0.085 \\
\hline & Fragment & 68.78 & 4 & 17.19 & 20.78 & $<0.0001$ \\
\hline & Use & 9.54 & I & 9.54 & 11.53 & 0.001 \\
\hline & Fragment*Use & 2.97 & 4 & 0.74 & 0.90 & 0.465 \\
\hline & Error & 414.46 & 501 & 0.83 & & \\
\hline \multirow[t]{15}{*}{ Akodon montensis } & PCI & & & & & \\
\hline & Intercept & 1.79 & 1 & 1.79 & 2.19 & 0.140 \\
\hline & Fragment & 75.06 & 5 & 15.01 & 18.29 & $<0.0001$ \\
\hline & Use & 49.27 & I & 49.27 & 60.05 & $<0.0001$ \\
\hline & Fragment*Use & 40.99 & 5 & 8.20 & 9.99 & $<0.0001$ \\
\hline & Error & 586.73 & 715 & 0.82 & & \\
\hline & PC2 & & & & & \\
\hline & Intercept & 0.01 & I & 0.01 & 0.02 & 0.900 \\
\hline & Fragment & 44.68 & 5 & 8.94 & 9.44 & $<0.0001$ \\
\hline & Use & 6.83 & 1 & 6.83 & 7.21 & 0.007 \\
\hline & Fragment*Use & 12.28 & 5 & 2.46 & 2.59 & 0.025 \\
\hline & Error & 677.11 & 715 & 0.95 & & \\
\hline & PC3 & & & & & \\
\hline & Intercept & 1.82 & I & 1.82 & 2.25 & 0.134 \\
\hline & Fragment & 103.50 & 5 & 20.70 & 25.67 & $<0.0001$ \\
\hline
\end{tabular}


Table 3: Full results of 2-way-ANOVA. Results of 2-way-ANOVA for all species and all three principal components. (Continued)

\begin{tabular}{|c|c|c|c|c|c|c|}
\hline & Use & 4.81 & $\mathrm{~T}$ & 4.81 & 5.97 & 0.015 \\
\hline & Fragment*Use & 5.07 & 5 & 1.01 & 1.26 & 0.281 \\
\hline & Error & $576 ., 55$ & 715 & 0.81 & & \\
\hline \multirow[t]{18}{*}{ Delomys sublineatus } & $\mathrm{PCI}$ & & & & & \\
\hline & Intercept & 2.87 & 1 & 2.87 & 4.53 & 0.034 \\
\hline & Fragment & 36.25 & 4 & 9.06 & 14.32 & $<0.0001$ \\
\hline & Use & 0.02 & I & 0.02 & 0.03 & 0.854 \\
\hline & Fragment*Use & 1.81 & 4 & 0.45 & 0.72 & 0.581 \\
\hline & Error & 318.98 & 504 & 0.63 & & \\
\hline & PC2 & & & & & \\
\hline & Intercept & 0.50 & I & 0.50 & 0.49 & 0.482 \\
\hline & Fragment & 30.53 & 4 & 7.63 & 7.58 & $<0.0001$ \\
\hline & Use & 1.40 & I & 1.40 & 1.40 & 0.238 \\
\hline & Fragment*Use & 5.37 & 4 & 1.34 & 1.33 & 0.256 \\
\hline & Error & 507.31 & 504 & 1.01 & & \\
\hline & PC3 & & & & & \\
\hline & Intercept & 2.05 & 1 & 2.05 & 2.47 & 0.117 \\
\hline & Fragment & 51.46 & 4 & 12.87 & 15.50 & $<0.0001$ \\
\hline & Use & 1.91 & I & 1.91 & 2.30 & 0.130 \\
\hline & Fragment*Use & 1.79 & 4 & 0.45 & 0.54 & 0.706 \\
\hline & Error & 418.38 & 504 & 0.83 & & \\
\hline \multirow[t]{18}{*}{ Marmosops incanus } & PCI & & & & & \\
\hline & Intercept & 2.08 & I & 2.08 & 2.47 & 0.117 \\
\hline & Fragment & 38.28 & 5 & 7.66 & 9.10 & $<0.0001$ \\
\hline & Use & 3.65 & I & 3.65 & 4.34 & 0.038 \\
\hline & Fragment*Use & 3.07 & 5 & 0.61 & 0.73 & 0.601 \\
\hline & Error & 500.42 & 595 & 0.84 & & \\
\hline & PC2 & & & & & \\
\hline & Intercept & 2.94 & I & 2.94 & 3.22 & 0.073 \\
\hline & Fragment & 39.16 & 5 & 7.83 & 8.57 & $<0.0001$ \\
\hline & Use & 3.98 & I & 3.98 & 4.36 & 0.037 \\
\hline & Fragment*Use & 8.75 & 5 & 1.75 & 1.92 & 0.090 \\
\hline & Error & 543.80 & 595 & 0.91 & & \\
\hline & PC3 & & & & & \\
\hline & Intercept & 1.65 & I & 1.65 & 1.95 & 0.163 \\
\hline & Fragment & 58.41 & 5 & 11.68 & 13.82 & $<0.0001$ \\
\hline & Use & 2.51 & I & 2.51 & 2.97 & 0.085 \\
\hline & Fragment*Use & 2.44 & 5 & 0.49 & 0.58 & 0.718 \\
\hline & Error & 503.02 & 595 & 0.85 & & \\
\hline
\end{tabular}

MENT*USE was found in any of the principal components (Table 3 ).

For M. incanus, however, there was a significant difference between mean values of used and unused trap locations in PC1 and PC2 (Table 3; Fig. 1), meaning that the species was captured more often in locations with higher canopy and less dense understory as well as in locations with a higher amount of horizontal structures. No significant interaction between factors FRAGMENT*USE was found for any of the principal components (Table 3).

\section{Discussion}

This study examined the response of individuals from five small mammal species to vegetation structure on a microscale and represents an extension of former studies by Pardini et al. [16] and Umetsu and Pardini [21] which assessed the influence of a larger scale (habitat) variation in vegetation structure and fragment size on small mammal populations in the same study area.

The results presented here revealed differences in vegetation structure among fragments as well as within fragments among trap locations. The observed major microscale trends in vegetation structure (as synthesized by the 


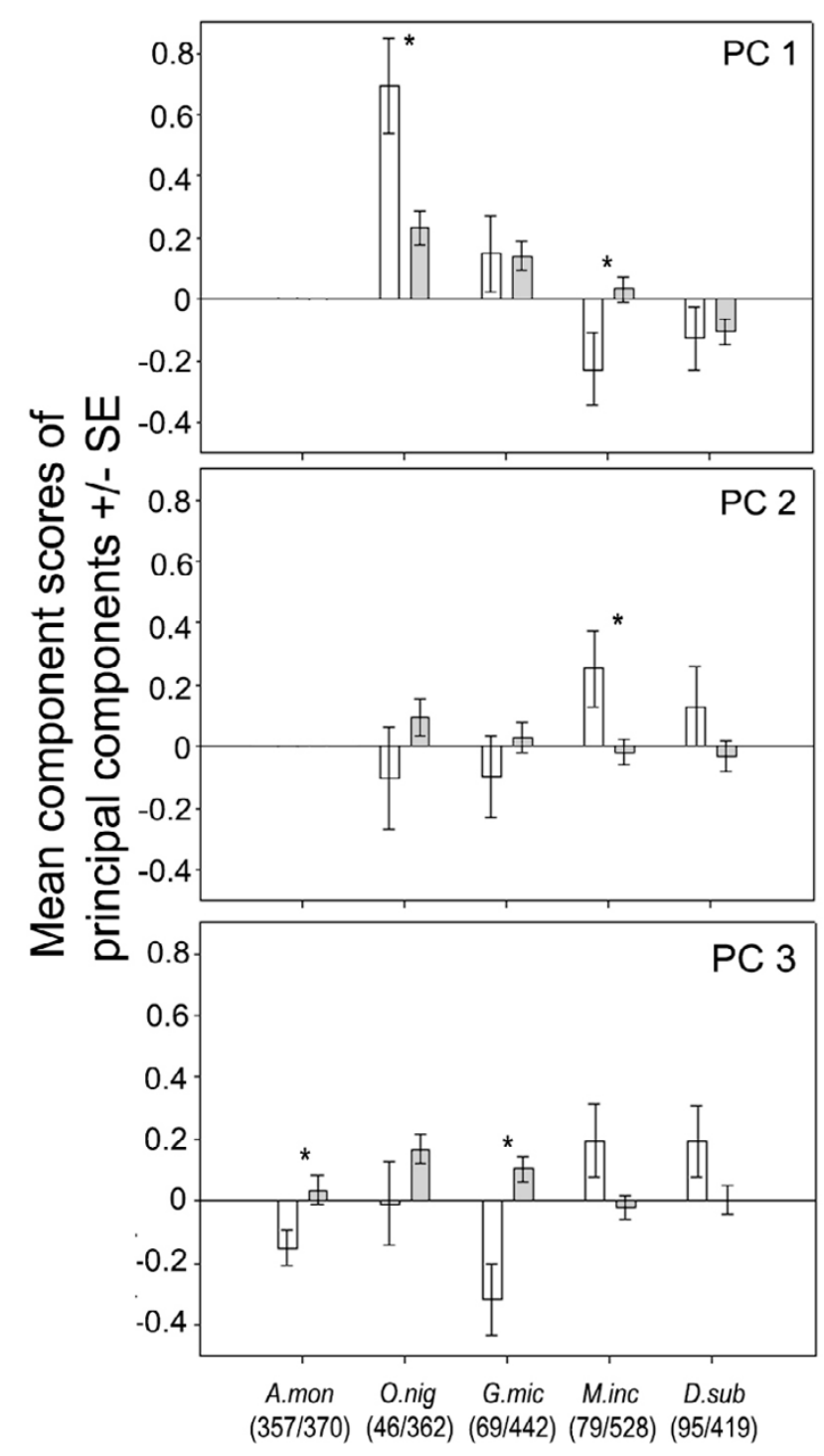

Figure I

Association between the occurrence of small mammal species and vegetation characteristics described by the three principal components. Comparison of mean (+/- standard error) component scores of used (open bars) and unused (grey bars) trap locations for $A$. montensis (A. mon), O. nigripes (O. nig), G. microtarsus (G. mic), D. sublineatus (D. sub), and M. incanus ( $M$. inc) and. Asterisks mark a significant difference between used and unused trap locations. Numbers of used/unused trap locations are given below. For $A$. montensis results of $\mathrm{PCl}$ and $\mathrm{PC} 2$ are not given because the use of vegetation described by these variables differed between fragments (significant interaction between FRAGMENT and USE).

three principal components) within the secondary forest fragments studied represented a gradient of forest succession/disturbance from old/undisturbed sites (higher can- opy height, less dense understory, less horizontal structures, denser canopy cover) to initial/disturbed sites (lower canopy height, denser understory, more horizontal structures, less dense canopy cover), similar to that observed on a larger scale (among habitat fragments) in Caucaia, from fragments of native vegetation in initial stage of regeneration (shrub vegetation) to fragments of native forest $[16,21]$.

These micro-scale differences in vegetation structure are probably caused by the interaction of several factors. Several studies pointed out a variety of factors influencing forest succession $[34,35]$. There are differences in colonization ability among plant species [35] which may lead to small scale differences in species composition and therefore secondary forest structure. Furthermore, abiotic and biotic conditions might differ between locations. For example, soil nutrients provide an important resource for colonizing plant species after forest clearing $[35,36]$ and are likely to vary due to pre-abandonment management. Furthermore, it has been hypothesized that differences in the occurrence of mycorrhizae might influence vegetation composition [37] and thus vegetation structure. Another cause of micro-scale variation in vegetation structure might be sporadic residual old-growth trees within the secondary vegetation [34] which can influence the surrounding habitat and also substantially increase canopy height at certain locations. Tree falls and the resulting gaps represent an additional source of small-scale variation within the forest [38]. Gaps in the canopy alter microclimatic conditions such as radiation, heat fluxes, wind, and humidity levels [39]. Other possible causes of variation are fire or cattle entering the forest. Although these events were not observed in the studied fragments during the study, they were relatively common in adjacent fragments and could have influenced studied fragments prior to data collection. Because not all parts of the trapping grids were located in equal distance from fragment edges, part of the variation might be due to edge effects. Because the proximity to edges influences several abiotic (micro-climate, windspeed, soil nutrients $[24,40]$ ) and biotic (invasion of non-forest species, species composition [41]) aspects of the habitat, edge effects may have severe influences on forest structure $[42,43]$.

Although vegetation structure differed among studied fragments most species responses to micro-scale variation were independent of the fragment considered, i.e. were similar in all fragments. The exception was some of the responses of one species non-vulnerable to fragmentation (A. montensis), which were influenced by the fragment considered. Thus, irrespective of the variation in vegetation structure among fragments, the distribution of all species except from $D$. sublineatus was influenced by micro-scale variation (within fragment) in vegetation 
structure. A. montensis and G. microtarsus were associated to locations with less canopy cover, while O. nigripes preferred locations with lower canopy and denser understory. On the contrary, M. incanus was captured in locations with higher canopy, less dense understory and higher amount of horizontal structures, while the distribution of D. sublineatus was not influenced by within-fragment vegetation variation.

The response group which preferred younger/more disturbed forest sites (A. montensis, O. nigripes, G. microtarsus) included a marsupial and rodents, terrestrial (A. montensis [44]) and scansorial (O. nigripes, G. microtarsus [44-46]) species, as well as insectivores/frugivores (all species [47$49]$ ) and granivores (rodents $[10,50]$ ), making taxonomic or ecological traits such as locomotor abilities or diet preferences poor predictors of the observed micro-habitat preferences. Nonetheless, both population response to larger scale (habitat) variation and to fragmentation are consistent with the micro-habitat preferences of this group: species preferring younger/more disturbed sites within secondary forest fragments (A. montensis, $O$. nigripes and G. microtarsus) were found to be able to occupy anthropogenic habitats and to be equally abundant in smaller and larger forest fragments [16,21].

On the contrary, the marsupial M. incanus, which preferred older/less disturbed sites inside secondary forest fragments was found to be restricted to patches of native vegetation and less common in initial stages of regeneration [21]. Although D. sublineatus was found to decrease in abundance in smaller and/or isolated forest fragments [16] and to be restricted to patches of native vegetation [21], this species presents similar abundance between patches of native vegetation in initial or latter stages of regeneration (22). Accordingly, we could not find any response of this species to micro-scale vegetation variation inside forest fragments.

Thus, our results indicate that patterns of habitat preference at the population level may be caused by individual responses at a smaller spatial scale (i.e., micro-habitat selection). Species whose individuals prefer younger/ more disturbed sites within secondary forest fragments would be able to establish populations in degraded habitats at larger spatial scales, thus being less vulnerable to fragmentation in the long run. On the other hand, species that do not show this preference for disturbed sites or whose individuals are restricted to old/non disturbed sites inside secondary forest fragments would not be able to established populations in degraded open habitats at larger spatial scales, being more vulnerable to fragmentation in the long run.
Studies on the responses of Atlantic Forest small mammals to habitat variation that include different spatial scales are rare (but see [51]). To our knowledge only two studies on microhabitat selection of small mammals in the Atlantic forest biome included partly the same species as in this study $[15,17]$. Fonseca and Robinson [15] investigated the selection of microhabitat from available habitat (measured as the mean of the variables obtained over all trapping stations) in primary and secondary semideciduous Atlantic forest for some small mammal species including $M$. incanus (all other species investigated by Fonseca and Robinson [15] were not subject to this study). They found no habitat selection in M. incanus, i.e. this species chose the microhabitat randomly from the available habitat. Dalmagro and Vieira [17] studied microhabitat of $O$. nigripes and $A$. montensis as well as of Delomys dorsalis, a congeneric of D. sublineatus, in Araucarian forest in south Brazil. Concurring with our results, they found that $O$. nigripes preferred areas in early successional stages within the forest. On the other hand, they also found that $D$. dorsalis preferred denser canopy cover and a positive correlation between canopy cover and the occurrence of A. montensis. Although it is difficult to directly compare these results given the heterogeneity in sampling design and data analysis among studies, these results may indicate that the response of the studied species to vegetation structure may vary among different types of forest in the Atlantic forest biome.

\section{Conclusion}

Results showed that major trends in micro-scale variation in vegetation structure within secondary forest fragments are similar to those observed at a larger spatial scale, i.e. among habitat fragments. This micro-scale variation in vegetation structure was shown to influence the distribution of most small mammal species in secondary forest fragments. Species that were shown to be able to establish populations in altered habitat and not to be vulnerable to fragmentation were clearly associated to younger/more disturbed sites within secondary forest remnants. On the contrary, species that were shown to be unable to establish populations in altered habitat and to be vulnerable to fragmentation preferred older/less disturbed sites or were not influenced by micro-scale variation in forest structure inside secondary forest fragments.

Thus the results, in combination with previous studies $[16,21]$, show that species responses are similar at different spatial scales of habitat and microhabitat, suggesting that microhabitat preferences may be an important factor influencing the capacity of small mammal to occupy altered habitats and, consequently, their vulnerability to forest fragmentation at a larger spatial scale. 


\section{Methods \\ Study area}

The study was conducted in the region of Caucaia do Alto $\left(23^{\circ} 40^{\prime} \mathrm{S}, 47^{\circ} 01^{\prime} \mathrm{W}\right)$ about $80 \mathrm{~km}$ south-west of the city of São Paulo, in a transition zone between dense ombrophilous forest and semi-deciduous forest classified as "Lower Montane Atlantic Rain Forest" [52] in the State of São Paulo, Brazil. Elevation ranges from 800 to $1100 \mathrm{~m}$ [53]. Monthly mean temperature range from a minimum of $11^{\circ} \mathrm{C}$ to a maximum of $27^{\circ} \mathrm{C}$. The annual precipitation level is $1300-1400 \mathrm{~mm}$ and fluctuates seasonally with the driest and coldest months between April and August.

The area includes a fragmented landscape, composed of secondary forest fragments embedded in an agricultural landscape, and an adjacent 10.000 ha forest reserve (Morro Grande Forest Reserve). Secondary forest covers $31 \%$ of the fragmented landscape, which is dominated by anthropogenic altered habitat (33\% agricultural fields, $15 \%$ areas with rural buildings or urban areas, $10 \%$ vegetation in early stages of regeneration, $7 \%$ pine and eucalyptus plantations, 4\% others). A more detailed description of the study area can be found in Pardini et al. [16].

\section{Study sites}

This study is part of a larger project investigating the effects of forest fragmentation on the small mammal community in Caucaia do Alto $[16,21]$. In the overall project several forest fragments differing in size and connectivity to other fragments as well as different plots in the continuous forest of the Morro Grande Forest Reserve were studied. To investigate the microhabitat preferences of small mammals, five forest fragments and one study site in the continuous forest were chosen, so that all sites were of secondary growth forest between 50 and 80 years old [54], but varied widely in terms of fragment size. Two sites were located in fragments of about 14 ha, two in fragments approximately twice as large ( $30 \mathrm{ha}$ ), one in a 175 ha fragment and one within secondary forest inside the Morro Grande Forest Reserve. The study sites were at least $8 \mathrm{~km}$ apart and movement of individuals between them was unlikely (and not detected). However, other forest fragments were in the vicinity of the study sites and inter-fragment movement between these fragments was possible.

\section{Trapping}

Regular trapping grids of one hundred trap locations $20 \mathrm{~m}$ apart from one another were established in all six study sites. One small and one large trap $(23 \times 9 \times 8 \mathrm{~cm}$ and 38 $\times 11 \times 10 \mathrm{~cm}$, respectively; Sherman Traps Inc., Tallahassee, USA) were set up at each trap location. One trap was put on the ground, the other one at an approximate height of 1.0 to $1.5 \mathrm{~m}$, alternating the positions of small and large traps from one trap location to the next.
Data collection was carried out during two trapping sessions in each of the study sites from March to June 2004 (1st session: 4.03.-7.04.2004, 2nd session: 18.05.26.06.2004). Each session consisted of six consecutive nights of capture, totalling 2400 trap nights per study site. The traps were baited with banana, and a mixture of peanut butter, oat and sardines. Traps were left open for the night, checked every morning and rebaited if necessary. Captured animals were anaesthetized (Forene ${ }^{\circledast}$, Abbott GmbH, Wiesbaden, Germany) for 1-2 minutes and marked individually by numbered ear tags (Fish and small animal tag size 1, National Band and Tag Co., Newport, Kentucky, USA). In addition to sexing and weighing, the length of their tibia was measured to the nearest 0.5 $\mathrm{mm}$ (measurements were taken for another study). All individuals were released at their respective trapping location.

\section{Vegetation characteristics}

Each of the 600 trap locations were characterized with respect to vegetation structure within a 5-meter radius around the trap locations according to August [55]. Vegetation characteristics were canopy height (estimated with the help of a marked 5-meter pole in meters and grouped into seven categories: $<6 \mathrm{~m}, 6.1-8.0 \mathrm{~m}, 8.1-10.0 \mathrm{~m}$, 10.1-12.0 m, 12.1-15.0 m, 15.1-20.0 $\mathrm{m}$ and 20.1-25 $\mathrm{m})$, canopy cover (estimations were based on a scale from 1 to 4 : 1 equals less than $25 \%$ cover while 4 counts for $76-$ $100 \%$ cover), vegetation density at 0 to $0.5 \mathrm{~m}, 0.5$ to 1.5 $\mathrm{m}$ and 1.5 to $3 \mathrm{~m}$ (estimations were based on a scale from 1 to 5: 1 indicates $20 \%$ of the specific strata is covered by plants, 5 indicates $81-100 \%$ of the specific strata is covered by plants), the amount of bamboo (estimations were based on a scale from 1 to 4 : 1 represents a percentage of cover of up to 25 of bamboo while 4 represents 76-100 percent bamboo) and the quantity of horizontal structures as an indicator of the connectivity of the vegetation above ground (1-4 scale: 1 means that few or no surrounding trees are connected by horizontal structures, 4 means a $76-100 \%$ of the surrounding trees are connected to each other by horizontal structures at any height).

\section{Statistical analysis}

The vegetation variables were standardized and reduced to three principal components (PC1, PC2 and PC3) to minimize correlation and to identify major traits of variation in vegetation structure (SPSS Principal Component Analysis, default settings, Varimax rotation).

We investigated if species distribution is influenced by micro-scale variation in vegetation structure and if these influences depend on the fragment where animals were captured. To test these hypotheses, we compared the scores of the principal components (dependent variables: PC1-PC3) using a factorial ANOVA, with FRAGMENT (1- 
6) and USE of trap locations (used and unused) as factors. Thus we investigated differences in principal component scores among fragments and between used and unused traps, as well as the existence of interactions between these two factors. Significant interactions indicate that the influence of micro-scale variation in vegetation structure is dependent on the fragment considered.

Only A. montensis and M. incanus were captured in all fragments. Other species were captured only in five (D. sublineatus, G. microtarsus) or four (O. nigripes) fragments. The component scores of all principal components deviated little from a normal distribution (Kolmogorov-SmirnovTest). In analysis of variance, non-normality of data can be tolerated, especially when sample size is large [56]. The assumption of homoscedasticity was tested by Levene's test for homogeneity of variances. Variances of PC1 and PC2 differed among fragments. ANOVA is robust to deviation from this assumption where sample size is large [56]. The comparison among fragments included six treatments with $n>=100$ each. With many samples or treatments the effect of any one sample variance on the estimated variances within treatments can only be small [56]. Therefore we continued with the analysis although Levene's test indicated heteroscedasticity in PC1 and PC2 among fragments.

We aimed to keep data independent of individual behavioural responses to capture. Therefore, only first-captured individuals of both capture sessions were considered [57]. Trap locations were weighted by the number of individuals captured at the respective location.

All tests were conducted on STATISTICA 6.0 (StatSoft Inc., Tulsa) using a significance level of 0.05.

\section{Authors' contributions}

TP, RP and YML participated in design of the study and data collection. TP performed the statistical analysis. TP and RP wrote the manuscript. SS conceived the study, participated in its design and helped to draft the manuscript. SS and RP participated in the project coordination. All authors read and approved the final manuscript.

\section{Acknowledgements}

We thank Jean-Paul Metzger and Fabiana Umetsu (University of São Paulo) as well as Christoph Knogge and Klaus Henle (UFZ Leipzig) for a very fruitful cooperation and scientific and logistic support. We also would like to thank Jörg U. Ganzhorn for supporting this study and helpful comments on statistical questions. We thank W.E. Magnusson and three unknown reviewers for their helpful comments on a previous version of this paper. We are grateful to Laura Sandberger, Anne Leppin, Claudia Guimaraes, Camilla Armstrong and Jürg Brendan Logue for field assistance. We appreciate the financial support provided by the BMBF Germany (German Federal Ministry of Education and Research, project ID: 0I LB 0202). This study is part of the BIOCASP project (Biodiversity conservation in fragmented landscapes on the Atlantic Plateau of São Paulo, Brazil).

\section{References}

I. Myers N, Mittermeier RA, Mittermeier CG, Fonseca GAB, Kent ]: Biodiversity hotspots for conservation priorities. Nature 2000, 403:853-858.

2. Galindo-Leal C, de Gusmão Câmara I: The Atlantic forest of South America: Biodiversity status, threats, and outlook. Washington, Covelo, London, Island Press; 2003:488.

3. Saatchi S, Agosti D, Alger K, Delabie J, Musinsky J: Examining fragmentation and loss of primary forest in southern Bahian Atlantic Forest of Brazil with radar imagery. Conservation Biology 200I, I 5(4):867-875.

4. Tews J, Brose U, Grimm V, Tielbörger K, Wichmann MC, Schwager $M$, Jeltsch $F$ : Animal species diversity driven by habitat heterogeneity/diversity: the importance of keystone structures. Journal of Biogeography 2004, 3 I :79-92.

5. Dunn RR: Recovery of faunal communities during tropical forest regeneration. Conservation Biology 2004, I 8(2):302-309.

6. Forget PM: Evidence for secondary seed dispersal by rodents in Panama. Oecologia 1991, 87:596-599.

7. Sánchez-Cordero V, Martínez-Gallardo R: Postdispersal fruit and seed removal by forest-dwelling rodents in a lowland rainforest in Mexico. Journal of Tropical Ecology 1998, I4:|39-I5I.

8. Brewer S, Reimánek M: Small rodents as significant dispersers of tree seeds in a Neotropical forest. Journal of Vegetation Science 1999, 10:165-174.

9. Vieira EM, Izar P: Interactions between aroids and arboreal mammals in the Brazilian Atlantic rainforest. Plant Ecology 1999, I 45:75-82.

10. Vieira EM, Pizo MA, Izar P: Fruit and seed exploitation by small rodents of the Brazilian Atlantic forest. Mammalia 2003, 67(4):533-539.

II. Pimentel DS, Tabarelli M: Seed dispersal of the palm Attalea oleifera in a remnant of the Brazilian Atlantic forest. Biotropica 2004, 36( I):74-84.

12. Janos DP, Sahley CT: Rodent dispersal of vesicular-arbuscular mycorrhizal fungi in Amazonian Peru. Ecology 1995, 76(6): 1852-1858.

13. Forget PM: Post-dispersal predation and scatterhoarding of Dipteryx panamensis (Papilionaceae) seeds by rodents in Panama. Oecologia 1993, 94:255-26I.

14. Pizo MA: Seed dispersal and predation in two populations of Cabralea canjerana (Meliaceae) in the Atlantic forest of southeastern Brazil. Journal of Tropical Ecology 1997, I 3:559-578.

15. Fonseca GAB, Robinson JG: Forest size and stucture: competitive and predator effects on small mammal communities. Biological Conservation 1990, 53:265-294.

16. Pardini R, Marques de Souza S, Braga-Neto R, Metzger JP: The role of forest structure, fragment size and corridors in maintaining small mammal abundance and diversity in an Atlantic forest landscape. Biological Conservation 2005, I 24:253-266.

17. Dalmagro AD, Vieira EM: Patterns of habitat utilization of small rodents in an area of Araucaria forest in Southern Brazil. Austral Ecology 2005, 30:353-362.

18. Pires AS, Koeler Lira P, Fernandez FAS, Schittini GM, Oliveira LC: Frequency of movements of small mammals among Atlantic coastal forest fragments in Brazil. Biological Conservation 2002 , 108:229-237.

19. Pardini R: Effects of forest fragmentation on small mammals in an Atlantic Forest landscape. Biodiversity and Conservation 2004, I3( I 3):2567-2586.

20. Viveiros de Castro EB, Fernandez FAS: Determinants of differential extinction vulnerabilities of small mammals in Atlantic forest fragments in Brazil. Biological Conservation 2004, I | 9:73-80.

21. Umetsu F, Pardini R: Small mammals in a mosaic of forest remnants and anthropogenic habitats - evaluating matrix quality in an Atlantic forest landscape. Landscape Ecology 2007, 22:517-530.

22. Püttker T, Meyer-Lucht Y, Sommer S: Fragmentation effects on population density of three rodent species in secondary Atlantic Rainforest, Brazil. Studies on Neotropical Fauna and Environment 2008, 43( I): I I- I8.

23. Vargas J, Simonetti JA: Small mammals in a tropical fragmented landscape in Beni, Bolivia. Mammalian Biology 2002, 69(I):65-69. 
24. Stevens SM, Husband TP: The influence of edge on small mammals: evidence from Brazilian Atlantic forest fragments. Biological Conservation 1998, 85: I-8.

25. Gascon C, Lovejoy TE, Bierregaard RO, Malcolm JR, Stouffer PC, Vasconcelos HL, Laurance WF, Zimmerman BL, Tocher M, Borges S: Matrix habitat and species richness in tropical forest remnants. Biological Conservation 1999, 91:223-229.

26. Turner MG: Landscape ecology: what is the state of the science? Annual Review of Ecology Evolution and Systematics 2005, 36:319-344

27. Morris DW: Ecological scale and habitat use. Ecology 1987, 68(2):362-369.

28. Morris DW: Scales and costs of habitat selection in heterogeneous landscapes. Evolutionary Ecology 1992, 6:412-432.

29. Schaefer JA, Messier F: Habitat selection as a hierarchy: the spatial scales of winter foraging by muskoxen. Ecography 1995, I 8:333-344.

30. Bowers MA, Gregario K, Brame CJ, Matter SF, Dooley Jr. JL: Use of space and habitats by meadow voles at the home range, patch and landscape scales. Oecologia 1996, I 05: 107-II5.

31. Bowers MA, Dooley Jr. JL: A controlled, hierarchical study of habitat fragmentation: responses at the individual, patch, and landscape scale. Landscape Ecology 1999, |4:38|-389.

32. Jorgensen EE: Small mammal use of microhabitat reviewed. Journal of Mammalogy 2004, 85(3):531-539.

33. Adler $\mathrm{GH}$ : Habitat selection and species interactions: an experimental analysis with small mammal populations. Oikos 1985, 45:380-390.

34. De Walt SJ, Maliakal SK, Denslow JS: Changes in vegetation structure and composition along a tropical forest chronosequence: implications for wildlife. Forest Ecology and Management 2003, I 82:|39-|5|.

35. Guariguata MR, Ostertag R: Neotropical secondary forest succession: changes in structural and functional characteristics. Forest Ecology and Management 200I, I48: I85-206.

36. Brown S, Lugo AE: Tropical secondary forests. Journal of Tropical Ecology 1990, 6:1-32.

37. Janos DP: Mycorrhizae influence tropical succession. Biotropica 1980, I 2(2 Suppl):56-64.

38. Felton A, Felton AM, Wood J, Lindenmayer DB: Vegetation struc ture, phenology, and regeneration in the natural and anthropogenic tree-fall gaps of a reduced-impact logged subtropical Bolivian forest. Forest Ecology and Management 2006 , 235: $186-193$.

39. Pinard MA, Cropper WP: Simulated effects of logging on carbon storage in dipterocarp forest. Journal of Applied Ecology 2000, 37:267-283.

40. Fischer J, Lindenmayer DB: Landscape modification and habitat fragmentation: a synthesis. Global Ecology and Biogeography 2007, 16:265-280

41. Harper KA, Macdonald SE, Burton PJ, Chen J, Brosofske KD, Saunders SC, Euskirchen ES, Roberts D, Jaiteh MS, Esseen PA: Edge influence on forest structure and composition in fragmented landscapes. Conservation Biology 2005, I 9(3):768-782.

42. Ries LR, Fletcher RJ, Battin J, Sisk TD: Ecological responses to habitat edges: mechanisms, models, and variability explained. Annual Review of Ecology and Evolutionary Systematics 2004, 35:491-522.

43. Malcolm JR: Edge effects in central Amazonian forest fragments. Ecology 1994, 75(8):2438-2445.

44. Fonseca GAB, Herrmann G, Leite YLR, Mittermeier RA, Rylands AB, Patton JL: Lista anotada dos mamíferos do Brasil. Occasional Papers in Conservation Biology 1996, 4: I-38.

45. Fonseca GAB, Kierulff MCM: Biology and natural history of Brazilian Atlantic forest small mammals. Bulletin of the Florida State Museum, Biological Sciences 1989, 34(3):99-I52.

46. Vieira EM, Monteiro-Filho ELA: Vertical stratification of small mammals in the Atlantic rain forest of south-eastern Brazil. Journal of Tropical Ecology 2003, 19:501-507.

47. Robinson JG, Redford KH: Body size, diet and population density of neotropical forest mammals. American Naturalist 1986 I 28(5):665-680.

48. Carvalho FMV, Pinheiro PS, Fernandez FAS, Nessimian JL: Diet of small mammals in Atlantic forest fragments in southeastern Brazil. Revista Brasileira de Zoociencias 1999, I(I):91-I0I.
49. Martins EG, Bonato V: On the diet of Gracilinanus microtarsus (Marsupialia, Didelphidae) in an Atlantic rainforest fragment in southeastern Brazil. Mammalian Biology 2004, 69(I):58-60.

50. Vieira EM, Paise G, Machado PHD: Feeding of small rodents on seeds and fruits: a comparative analysis of three species of rodents of the Araucaria forest, southern Brazil. Acta Theriologica 2006, 5 I (3):3 ||-3|8.

5I. Moura MC, Caparelli AC, Freitas SR, Vieira MV: Scale-dependent habitat selection in three didelphid marsupials using the spool-and-line technique in the Atlantic forest of Brazil. Journal of Tropical Ecology 2005, 21 :337-342.

52. Oliveira-Filho AT, Fontes MAL: Patterns of floristic differentiation among Atlantic Forests in Southeastern Brazil and the influence of climate. Biotropica 2000, 32:793-8I0.

53. Ross JLS, Moroz IC: Mapa Geomorfológico do Estado de São Paulo: escala I:500.000. FFLCH-USP. In São Paulo, IPT and Fapesp; 1997.

54. Godoy Teixeira AM: Análise da dinâmica da paisagem e de processos de fragmentação e regeneração na região de Caucaia-do-Alto, SP (1 962-2000). In Department of Ecology São Paulo , University of São Paulo; 2005

55. August PV: The role of habitat complexity and heterogeneity in structuring tropical mammal communities. Ecology 1983, 64(6): | $495-1507$

56. Underwood AJ: Experiments in ecology: their logical design and interpretation using analysis of variance. Cambridge , Cambridge University Press; 1997:504.

57. Gentile R, Fernandez FAS: A field comparison of two capturemark-recapture estimators of small mammal populations. Revista Brasileira de Zoologia 1999, I 6(4): I I09-I I |4

58. Emmons LH, Feer F: Neotropical rainforest mammals: a field guide. 2nd edition. Chicago , The University of Chicago Press; 1997:307.

59. Tyndale-Biscoe H: Life of Marsupials. Collingwood, CSIRO Publishing; 2005:464.
Publish with Bio Med Central and every scientist can read your work free of charge

"BioMed Central will be the most significant development for disseminating the results of biomedical research in our lifetime. "

Sir Paul Nurse, Cancer Research UK

Your research papers will be:

- available free of charge to the entire biomedical community

- peer reviewed and published immediately upon acceptance

- cited in PubMed and archived on PubMed Central

- yours - you keep the copyright
BiolMedcentral 